\title{
Evaluating the Effects: A Contribution to the Quality of Legislation
}

\author{
LUZIUS MADER*
}

\section{The development of legisprudence}

During the last three decades, legislation has become an important field of scientific interest and practical training. At least in the German speaking countries, Peter Noll was one of the pioneers of a new, comprehensive approach to legislation. ${ }^{1}$ It is an approach which has been widely adopted in an effort to improve the quality of legislation. Neither has it been limited to legal science for it concerns a wide range of academic disciplines interested in various aspects of the legislative activity. Nor does it solely have an academic focus, for it encompasses practical considerations.

Legislative problems are, to some extent, universal problems; they should be dealt with in a multidisciplinary way, and they have a practical as well as a theoretical dimension. The term "legisprudence" that is sometimes used to describe these different elements and to stress the links between the different aspects of modern legislative studies expresses in a very appropriate way the character of this new, comprehensive approach. ${ }^{2}$ Legisprudence aims at furthering the theoretical understanding as well as the technical handling of legislation; it combines elements of science, art and craftsmanship; it concerns both the content of legislation and its form.

Within legisprudence various particular areas of interest may be distinguished:

\footnotetext{
* Vice-Director, Federal Office of Justice, Berne; Professor at the Institut de hautes études en administration publique (IDHEAP), Lausanne.

1 Peter Noll, Gesetzgebungslehre, 1973.

2 See e.g. W. Voermans/Philip Eijlander, Working out the fundamentals for a broader crossing post-instrumental doctrine on legis-prudence, in: Charles-Albert Morand (ed.), Légistique formelle et materielle-Formal and Material Legistic, 1999, pp. 47ss; see also Luzius Mader, Legislative Procedure and the Quality of Legislation, in: Ulrich Karpen/Paul Delnoy (eds), Contributions to the Methodology of the Creation of Written Law, 1996; p. 62; the term "legisprudence" has first been used-in French—by Luc Wintgens: see Luc Wintgens, Création d'une banque de données en "légisprudence", in: Gesetzebung heute 1992, vol. 3, p. 91.
} 
(i) legislative methodology (or material (substantive) legistic ${ }^{3}$ ): deals with the content of legislation; proposes a methodical way of elaborating normative contents and develops practical tools facilitating the different steps or phases of this methodical approach.

(ii) legislative technique (formal legistic in the narrow sense): deals with formal aspects of legislation, with the different types of normative acts, with their formal structure, etc.;

(iii) legislative drafting ${ }^{4}$ : concerns linguistic aspects of legislation, the way of expressing normative contents by normative texts;

(iv) legislative communication: the publication of normative texts or, more generally, the way of communicating normative contents, including a broad range of information about legislation, not only the official publication;

(v) legislative procedure ${ }^{5}$ : the process of elaborating, enacting and implementing legislation follows procedural rules of various kinds; these rules may influence to some extent the formal and the material or substantial quality of legislation; they may further or hinder the methodical approach of the legists, i.e. of the persons preparing new legislation;

(vi) the management of legislative projects: preparing legislation may be seen as a task for which the principles and techniques of project management are applicable;

(vii) the sociology of legislation: the political process preceding the enactment of legislation, the implementation process and the effects of legislation are an important field for sociological studies and an essential element of legisprudence;

(viii) the theory of legislation: consideration of the role or function of legislation as an instrument of social guidance and control by the State.

Although general legislative problems have a universal character, the more practically oriented dimensions of legisprudence-and, above all, the solutions practised in fields such as legislative technique and drafting, legislative procedure and even management of legislative projects-are closely linked to particular national contents and are circumscribed by national legal rules. For this

${ }^{3}$ For the distinction between formal and material legistics see Charles-Albert Morand, Eléments de légistique formelle et matérielle, in: Charles-Albert Morland (ed.), Fn 2, pp. 17ss.

4 "Drafting" is used here in a narrow sense. In common law countries legislative drafting generally includes linguistic aspects, the writing of normative texts, as well as other aspects of formal legistic; for the draftsman's functions and the drafting process see David R. Miers/Alan C. Page, Legislation (second edition) (Sweet \& Maxwell 1990) in particular pp. 51ff. Unlike Great Britain and countries influenced by the British tradition in this field, in continental European Countries legislation is not usually drafted by special drafting services but by the administrative units responsible for the policies or their legislative implementation.

${ }^{5}$ Legislative procedure and legislative process are closely interrelated. See in this context also Michael Zander, The law-making process (fourth edition): 1994. 
reason, the practical training of legists, persons involved in the preparation of legislation, is closely associated with their institutional and legal environment.

Whereas legislative drafting or, in a broader sense, formal legistic is mainly an affair for lawyers, material legistic is by no means an exclusivity of persons with legal training or a field of activity for which lawyers are necessarily better prepared than persons having another professional background. This is true, in particular, for the different sequences of the methodical approach, including evaluation, for the management of legislative projects and for the sociology of legislation. For dealing with the material or substantial aspects of the legislative work, lawyers-at least lawyers with a traditional legal education-are not better equipped than anyone else. However, their predominant and privileged position in the drafting stage of the legislative process has also given them a particular responsibility for the material aspects of legislation.

\section{Evaluation as an essential part of legislative methodology}

The evaluation of legislative forms, on the one hand, an important-and at least in some fields traditional ${ }^{6}$ - element of the sociology of legislation. On the other hand, it is also an essential part of legislative methodology. Unlike legislative drafting, it thus concerns the substantive rather than the formal aspects of legislation and it is particularly concerned with the relation between normative contents and their consequences in the social reality, in the "real world".

The methodical approach recommended for elaborating normative contents is based on the separation of different analytical steps or sequences. These steps include:

(1) the analysis and definition of the problem that legislative action presumes to solve;

(2) the determination or clarification of the goals of legislation;

(3) the examination of legal instruments or means that can be used to solve the problem and the choice of such instruments (based-among other things-upon a prospective evaluation of their possible effects);

(4) the drafting of the normative content;

(5) the formal enactment;

(6) the implementation;

(7) the retrospective evaluation; and

\footnotetext{
${ }^{6}$ This is particularly true for the field of criminology and, to a lesser degree, some fields of private law. In the field of public law, however, the main impulse for the development of evaluation came from the political sciences, not from the sociology of law.
} 
(8) if necessary or appropriate, the adaptation of legislation on the basis of the retrospective evaluation.

The analytical model underlying the methodical approach to the preparation of legislation considers the legislative process as a reiterative learning process. It is a process in which the evaluation of the effects of legislation is a fundamental prerequisite, and which ensures that the legislator is responsive to social reality and the social adequacy of legislative action.

Of course, this methodical approach to legislation has its limitations. In particular, it is an approach, which is essentially based on an instrumental view of legislation; legislation is concerned as an instrument of social guidance and control, as a tool of social engineering. In other words, this approach is based on the assumption that legislation is a rational activity that is aimed at realising specific purposes or goals, at achieving specific results in the social reality.

This assumption may be questioned. It is only partly accurate. Not all legislation has an instrumental character; or, at least, the instrumental character of legislation is not always predominant. It is, for example, likely to be more important in the field of public law than in the field of private law. Furthermore, in some cases, legislation may be seen more realistically as the expression of political constraints rather than as an attempt to solve a problem by changing the behaviour of those to whom it is addressed. It may sometimes be seen, also, as a more or less fortuitous result of political debate and compromise rather than as a rational effort to bring about social change. It may be seen, finally, as a symbolic act without any real ambition to produce practical results. Symbolic in the sense that its main function can be to express the political authorities' awareness of a problem, their willingness to share public preoccupations, an expression that they are concerned and feel the need to show that the situation is under control. In this sense, the instrumental, rational view of legislation underlying the methodical approach has only a partial validity. Nevertheless, in many cases legislation undoubtedly has a predominantly instrumental character, or at least an instrumental purpose. Here the methodical approach is reasonable and appropriate.

With these preliminary observations it may be useful to explore what is meant by "evaluation" in the context of legisprudence. ${ }^{7}$ The word "evaluation" is now used in so many diverse ways and senses that definition is difficult. ${ }^{8}$

\footnotetext{
${ }^{7}$ See in particular Charles-Albert Morand/Jean-Louis Bergel (ed.), Evaluation législative et lois expérimentales, 1993; Faculté de droit et de science politique d'Aix-Marseille (ed.), L'évaluation législative, in: Cahiers de méthodologie juridique No 9/Reveue de la recherche juridique-Droit perspectif 1994/4; Charles-Albert Morand, Formes et fonctions de l'évaluation législative, in LeGes 1992/2, pp. 79ss; Luzius Mader, L'évaluation législative-Pour une analyse empirique des effets de la législation, 1985

${ }^{8}$ Terminological diversity is, of course, also due to the fact, that evaluative approaches have been developed in different academic disciplines and in different national contexts.
} 
"Evaluation" means the analysis and assessment of the effects of legislation.9 This very general definition contains three elements.

First, evaluation has to do with legislation, with normative acts and by implication, with the administrative decisions based on them. Formally its object therefore differs from that of policy analysis. However, at least where the rule of law is respected, there is no fundamental difference in practice between the evaluation of legislation and the evaluation of public policy. ${ }^{10}$

Second, evaluation is concerned with the causal relations between legislative actions and social reality. It is interested in the effects. It examines the extent and consequences of changes in attitude, behaviour and circumstance that are potentially or actually due to legislative action.

Third, evaluation tries to analyse and assess the effects of legislation in a methodical way. This analysis and assessment has three important characteristics. It is undertaken in a manner that can be generally understood and followed, in particular because it clearly identifies the bases for the statements or judgements about the, potential or actual, causal connections between legislative enactments and the observable social reality. It is as systematic as possible, in that it takes into account all relevant effects. It is as objective as possible, in that it is not driven by particular interests.

The written results of evaluations satisfying these three requirements may be published, or at least communicated to interested persons or institutions, and critically examined. Defined in this pragmatic sense, evaluations are, on the one hand, clearly much more than purely impressionistic, intuitive political appraisals; on the other hand, they do not necessarily comply with the most severe criteria of a truly scientific analysis. They take into account intuitive assessments of the effects of legislation made by the relevant political actors or target groups, build on practical experiences and especially on the specific knowledge held by the authorities implementing legislation and try to complete this knowledge by methodical analysis including often, but not invariably, the use of various science methods. In other words, evaluations are a pragmatic attempt to produce more relevant and more accurate information about the potential or actual causal relationships between legislative action and observable social attitude, behaviour or circumstance.

Such causal relationships are very often extremely difficult to analyse. Social causality is very complex. In most cases, it cannot be proven in a strict sense. However, this does not diminish the importance or even the necessity of evaluation. For at least if we accept the relevance of the instrumental perspective on

\footnotetext{
9 For this definition and the following comments see for example the report prepared by a working party set up by the Swiss Ministry of Justice: Département fédéral de justice et police, Mieux connaître les effets de l'action étatique: problèmes, possibilités, propositions (Rapport final du groupe de travail "Evaluation législative"), 1991, Berne.

${ }^{10}$ For the evaluation of public policy see e.g. Werner Bussman/Ulrich Klöti/Peter Knoepfel (ed.), Einführung in die Politikevaluation, 1997; see also Katia Horber-Papazian, Evaluation des politiques publiques en Suisse, 1990.
} 
which the methodical approach to law-making is founded, the legislator inevitably assumes the existence of such causal relations. Legislative action is, explicitly or implicitly, based on assumptions relating to causal relations. The main purpose of evaluation is not to prove that these assumptions are right or wrong. It is to ensure:

(1) that the causal assumptions underlying legislative action are as explicit and as differentiated as possible when new legislative initiatives are prepared;

(2) that they are based on the best possible theoretical basis and the most reliable information that is reasonably available;

(3) and that their accuracy is examined after the legislation is adopted and brought into force.

In short: evaluation is a pragmatic effort to improve the legislator's assumptions and knowledge about the effects of legislation. It aims at more plausibility in this field, not at certainty or scientific proof.

\section{Prospective and Retrospective Evaluation}

In accordance with the analytical model underlying legislative methodology evaluation should be undertaken both before and after the formal enactment of legislation. We have to distinguish, therefore, between two different perspectives or between two different types of evaluation: prospective (ex ante) and retrospective (ex post) evaluation.

Perspective evaluation is made before taking formal legislative decisions in order to have a better insight into the possible or potential effects of planned legislation. It may, in particular, assist in choosing the appropriate provisions for solving a legislative problem. Retrospective evaluation is made once the legislation is in force or, in some cases, especially if the norms are only in force for a limited time, shortly before or after the end of that period. The purpose is to have a better knowledge of what happens after the legislation is in force ${ }^{11}$ and to discover the real effect of the legislative action.

This distinction is important, in particular because the tools, the methods and techniques used for evaluating the effects differ between the two types of evaluation. However, even in a methodological context, these differences should not be exaggerated. In fact, from the practical perspective, the two forms of evaluation are largely complementary. Prospective efforts to assess methodically the possible effects of draft legislation facilitate considerably retrospective evaluation; the more explicit and differentiated prospective evaluation is, the

${ }^{11}$ See the subtitle of a classic in the field of implementation and evaluation studies: Eugen Bardach, The Implementation Game-What Happens After a Bill Becomes a Law, 1977. 
easier it is to get reliable information retrospectively because it furthers the awareness of the current lack of knowledge and provides an impetus for releasing it. Legislation may even provide for the necessary data to be collected. And on the other hand, good retrospective evaluation helps to create a more solid basis for prospective evaluation, because it produces useful comparative data and encourages the development of theoretical insights that permit a more accurate prognosis of the effects. For these reasons, the same attention has to be paid to both types of evaluation and they have to be developed simultaneously.

\section{Experimental Legislation}

A particular form of legislation which should be mentioned in this context is experimental legislation. This is legislation enacted for a limited period of time in order to examine if a particular legislative measure will effectively achieve certain goals. Experimental legislation is enacted with a prospective purpose, but from the methodological point of view it requires retrospective evaluation. ${ }^{12}$

Of course, every legislative initiative may in a sense be characterised as experimental in nature; it can be seen as being part of a learning process based on trial and error. However, this is not what is meant by the expression "experimental legislation". Strictly speaking, experimental legislation is a form of legislation displaying particular characteristics: it should be limited in time; it should clearly state its purpose; it should specify the goals of the planned legislative action and indicate the criteria used to evaluate if the provisions adopted on a temporary basis are appropriate; it should specify the data to be collected and define the responsibilities for collecting the data and for assessing the results, and so on.

Relative simple examples of such experimental legislation can be found in the field of traffic legislation, in particular norms relating to speed limits. A recent and very instructive Swiss example is the legislation enacted some years ago to test the effects of the medical distribution of heroin to persons addicted to hard drugs. ${ }^{13}$ Based on the convincing results of this evaluation, Switzerland has in the meantime decided to introduce the experimental measures on a permanent basis. As these measures were politically very controversial, it was essential to make sure that the evaluation led to reliable results.

\section{Evaluation Criteria}

Evaluation is concerned with the effects of legislation. They are its main object; an object that presents different aspects, that can be considered from various

${ }^{12}$ For some recent examples of experimental legislation in Switzerland see Luzius Mader, La législation expérimentale en Suisse, in Charles-Albert Morand/Jean-Louis Bergel, ed. (Fn. 7), pp. 221ss.

${ }^{13}$ See Ordonnance du 21 octobre 1992 sur l'évaluation de projets visant à prévenir la toxicomanie et à améliorer les conditions de vie des toxicomanes, Recueil systématique des lois fédérales 812.121.5. 
points of view and assessed with regard to different criteria. The most frequently mentioned evaluation criteria are: effectiveness, efficacy and efficiency. ${ }^{14}$

Effectiveness is the extent to which the observable attitudes and behaviours of the target population (individuals, enterprises, public officials in charge of the implementation or enforcement of legislation) correspond to, and are a consequence of, the normative model; that is, to the attitudes and behaviours prescribed by the legislator. Two questions have to be asked here: Is the norm respected or implemented? And can the correspondence between the observable degree of respect or implementation be imputed to the norm or not? For some types of norms, in particular for orders, injunctions or prohibitions, the word "compliance" may be used at least for the first question. For others, such as norms concerning the granting of permits or subsidies by state authorities, the word most frequently used is "implementation". From a traditional legal perspective, it is the effectiveness of legislation that is very clearly the centre of interest.

Efficacy is the extent to which legislative action achieves its goal. This criterion is particularly interesting from a political point of view and it shows also how important it is to define clearly the goal or the goals of a legislative proposal: if the political authorities, the legislator, fail to define the goals, it is impossible to assess the efficacy of legislation. This does not necessarily mean that the goals have to be explicitly mentioned in the normative act itself. They may also be expressed in a report accompanying a legislative proposal or formulated during the parliamentary debate. Without such a politically "authorised" definition of the goals, evaluators have to define themselves what they consider to be the relevant goals of particular legislation.

Effectiveness is a condition, but not necessarily a guarantee of the efficacy of legislation. It contributes to the efficacy only if the causal assumptions implicitly underlying the legislator's choice of provisions are accurate. On the other hand, the simple fact, that the goals of a particular legislation are realised does not necessarily prove the efficacy of this legislation; the realisation of the goals may result from other factors.

Efficiency is the relation between the "costs" and the "benefits" of legislative action. ${ }^{15}$ The word "costs" and "benefits" are used in this context in a very

14 The terminology may vary considerably; it is important, however, to clearly distinguish the different concepts. Political scientists interested in the evaluation of public policies often distinguish in this context between 'output", "impact" and "outcome"; this is so not only in Anglo-Saxon but also in French or German literature. In this analysis, "output" means in particular the implementation activities induced by a public policy, "impact" stands for behavioural changes of the target population of a public policy and "outcome" for the consequences of these changes. With regard to the goals of the public policy; see for example Werner Bussmann et al., ed. (Fn 10), pp. 72s. However, these three concepts do not fully coincide with the concepts "effectiveness", "efficacy" and "efficiency".

15 See in this context the papers presented at the conference "Cost-Benefit Analysis: Legal, Economic and Philosophical Perspectives", held at the University of Chicago Law School on September 1718, 1999; the papers are published in the Journal of Legal Studies, vol. XXIX (June 2000); see in particular Richard A. Posner, Cost-Benefit Analysis: Definition, Justification, and Comment on Conference Papers, ibid., pp. 1153ff. See also Bruno Binder et al., Berechnung und Abschätzung der Folgekosten von Gesetzen in Österreich, 1999; this study concerns in particular the prospective 
broad sense. The first includes not only the direct financial consequences of the implementation of, and compliance with, legal norms; it also takes into account non-material factors, such as psychological or emotional inconvenience, and even all negative effects of the legislation. The second refers mainly to the goals of the legislative action; all effects which are compatible with these goals, or further their realisation, can be considered as benefits. Evaluating the efficiency of a legislation means therefore considering, its costs and also the extent to which its goals are achieved. This assists the choice between various measures and a judgement on whether a measure is a proportional response to the goal which is sought. The assessment of the costs and benefits is made primarily from the perspective of the legislator and the public sector. However, it can, of course, take into account other perspectives, especially that of those on whom the legal norms is targetted. In this sense, a distinction can be made between internal and external costs and benefits.

These three criteria of effectiveness, efficacy and efficiency highlight some aspects of the effects of legislation; they emphasise aspects that are particularly important in the law-making process. However, they do not exhaustively reveal the complex causal relationships which are the reality of society. They do not necessarily encompass all the relevant effects of a particular legislative action, sometimes designated by the word impact. A practical example may illustrate this. In most countries, the drivers of, and sometimes passengers in, cars have to wear a safety belt. The legal obligation is supposed to reduce the injuries in case of an accident. The effectiveness of this norm seems to vary considerably. At least in some countries or areas a relatively high proportion of drivers wear safety belts and they do so, partly at least, because a legal obligation exists (effectiveness). There is evidence, that wearing a safety belt contributes to the reduction of injuries (efficacy). The costs of this measure (technical equipment in the cars, implementation activities of public authorities; in a broader sense also the physical and psychological constraints for the drivers and passengers) are not disproportionate compared with the extent to which this measure contributes to the reduction of injuries (efficiency). Nevertheless, there seems to be some evidence that the measure also produces negative effects, that could lead to more sceptical conclusions. In particular, wearing safety belts seems to result in adverse changes in attitudes or capacities of drivers, resulting in more accidents and particularly in more serious injuries caused to cyclists and pedestrians. Therefore, the evaluation of the overall impact of this measure probably has to accommodate further considerations.

\section{Evaluation Tools and Methods}

Evaluating the effects of legislation means, in the first instance, developing sensible assumptions about the-potential or real—causal connections between

evaluation of the efficiency of legislation in Austria, but it takes also into account experiences and practices in other European countries as well as in the European Union. 
legal norms and observable attitudes, behaviours and circumstances. Secondly, it requires that the validity of these assumptions is tested by using all the relevant experience, information and knowledge that is available or can be made available in a reasonable time and with a reasonable effort.

From the legists' point of view, one of the most important questions is how an evaluation can be made in practice. What are the tools, methods and techniques can be used to evaluate the effects of legislation? The answer varies as a result of, among other things, the particular circumstances of each case, the specific criteria that are to be considered, the perspective (ex ante or ex post) and the degree of plausibility and reliability of the results. Evaluating prospectively the effects of a change in fiscal legislation on private saving does not call for the same techniques as evaluating retrospectively the effectiveness of newly introduced security standards in the field of construction or of the efficacy of new procedural rights in favour of disabled persons with regard to the principal of equal treatment. An evaluation which aspires to a scientific or quasi-scientific character needs an investment that is incomparably higher than an evaluation seeks an intuitive or impressionistic political assessment by a systematic use of practical knowledge and experience available within the responsible administrative service.

The best and most reliable retrospective evaluations use the different qualitative and quantitative methods and techniques familiar in the field of social sciences: for example, interviews, observation, text analysis, synchronic and diachronic statistical comparisons between target populations and populations not exposed to legal change. ${ }^{16}$ Prospective evaluations rely on techniques such as practical tests, demonstration programs, modelling, simulations, forecasting, systems analysis and scenario building. ${ }^{17}$ In other words: for prospective as well as for retrospective evaluation there is a large variety of very sophisticated tools that can be used separately or, better, in combination ("triangulation") in order to get the most reliable and accurate results.

However, we have to be aware, first, that even these sophisticated tools have their methodological limits: they can rarely provide absolute certainty about causal connections, but they undoubtedly sharpen the legists' and the lawmakers' sensibility of this crucial aspect of legislative activity. They may, to some extent, reduce uncertainty and, in this way, contribute to improving the substantive quality of legislation. And, second, we have to be aware also of the practical limits that exist in the legislative process; applying these sophisticated evaluation tools needs time, money and it must also be recognised that there

${ }^{16}$ For a practical example see Reinhard Giese und Peter Runde, Wirkungsmodell für die empirische Bestimmung von Gesetzeswirkungen-Modellansatz und Anwendung im Rahmen einer Wirkungsanalyse zur Pfegeversicherung, Zeitschrift für Rechtssoziologie 1999/1, pp. 14ss.

${ }^{17}$ For a good overview see United States General Accounting Office, Prospective Evaluation Methods: The Prospective Evaluation Synthesis, 1990; see also Werner Bussmann, Die Methodik der prospektiven Gesetzesevaluation, in LeGes 1997/3, pp. 109ss; for a practical example see Carl Böhret/Götz Konzendorf, Rechtsoptimierung mittels Gesetzesfolgenabschätzung: Waldgesetz Rheinland-Pfalz, 1998. 
are practical limitations within personal resources that are not always available in practice.

Even where legists are not able to use these tools, they should at least know in which situations it would be possible and helpful to use them. And for practical reasons, the legists often have to choose more modest tools; tools which are perhaps more appropriate to develop causal assumptions than to test them but which are nevertheless very helpful. Two such tools, which can certainly be used as auxiliary instruments should be mentioned in this context: the typology of the effects of legislation and the graphic presentation of causal connections.

The typology of the effects of legislation, distinguishes different categories of effects, for example intentional and non-intentional effects, expected and unexpected effects, beneficial and adverse effects, direct and indirect effects, immediate and delayed effects. These distinctions are able to sharpen the legists' sensibility and awareness for the complexity and the multiple dimensions of causal relationships in social reality.

The graphic presentation of causal connections between a legal norm and the observable social reality is a way of visualising the causal hypothesis. It helps to reconsider critically and examine this hypothesis. Of course, graphic modelling inevitably reduces the complexity of the potential or real causal connections. In practice, however, it helps considerably to become aware of certain weaknesses and shortcomings of the hypotheses that have been developed or of the analysis of causal connections. The analysis of the system of relevant social and institutional actors, the goals of the particular legislation and the areas of activity affected by the legislative action are useful starting points for establishing such a graph.

\section{The Institutionalisation of Evaluation}

In the last thirty years, evaluation has become a quite important element in the legislative practice of many countries. To some extent it has been institutionalised, ${ }^{18}$ and this may take the form of either procedural or organisational measures. ${ }^{19}$

Examples of procedural measures are evaluation clauses (creating an obligation

18 The new Federal Constitution of the Swiss Confederation of April 18, 1999, provides in art. 170 that "The Federal Parliament shall ensure that the efficacy of measures taken by the Confederation is evaluated". In spite of its rather narrow wording, this provision is interpreted as a general obligation to ensure the evaluation of the effects of legislation; it does not mean, however, that Parliament itself has to evaluate the effects of legislation. For a general overview concerning the present situation and the future of evaluation in Switzerland see Thomas Widmer et al., Stand und Aussichten der Evaluation beim Bund, 2001.

19 See for example Ingo Unkelbach, Die Institutionalisierung der Gesetzesfolgenabschätzung auf Landesbene, 1998; this author examines the different possibilities of institutionalising evaluation in the German Länder. 
to make prospective and/or retrospective evaluations) or obligations to make periodic reports. ${ }^{20}$ A particular form is "sunset legislation" which has been used over a period, particularly in some States of the USA. Sunset legislation is limited in time and can only be renewed on the basis of a report confirming that it is necessary and appropriateness.

Organisational measures concern the creation of special units responsible for the evaluation of legislation. They may be created within the different ministries (decentralised solution), in one particular ministry (centralised solution), within the parliamentary services or as autonomous bodies. They may themselves evaluate the effect of legislation or commission external specialists to do so.

Institutionalising evaluation has advantages. It makes it easier to take into account methodological aspects and requirements during the preparation of the legislation. It guarantees that the necessary financial and personal resources are available when needed. It encourages an optimal synchronisation of evaluation with the legislative decision-making process and thus optimises the integration of the results of an evaluation in this process. It may facilitate the collaboration of the administrative bodies responsible for the implementation of legislation and in particular the access to, or the availability of, relevant data. It may lead to an impartial, more objective approach; and, finally, it gives greater legitimacy and therefore more political weight to the results of evaluation.

\section{Final remarks}

Evaluation of legislation, be it prospective or retrospective, is an indispensable element of any methodical, rational approach to law-making. These methodical approaches are all based on an essentially instrumental view of legislation. Evaluation tries to contributor-and, to some extent at least, succeeds in contributing-to the material quality of legislation as an instrument of social change. In this sense, evaluation is a technocratic tool. As such, it can and should be used in a pragmatic and selective way, with the necessary awareness of its methodological and practical limitations. Evaluation is not a panacea. It would be wrong, therefore, to practise it generally, as an imperative part of legistic routine. As a French sociologist of law stated more than twenty years ago, the rationalisation of legislative choices becomes unreasonable when it exceeds certain limits of cost and time; beyond a certain threshold, the arbitrariness of the legislator becomes reasonable. ${ }^{21}$

Reasonably practised, however, evaluation is more than a technocratic tool.

${ }^{20}$ In Switzerland, today, nearly 50 Federal Statutes and ordinances enacted by the government contain such evaluation clauses, one of them, art. 43 of the Federal Statute on the relationship between the Councils, Recueil Systématique des lois fédérales 171.11 concerning specifically prospective evaluation

${ }^{21}$ Jean Carbonnier, Sociologie juridique, 1978, p. 412. 
From a legal or juridical point of view, the improvement of our knowledge about the effects of legislative action may give a new sense and a new importance to general legal or constitutional principles such as the principle of equality before the law, the protection against arbitrariness and, in particular, the principle of proportionality. In this sense, it contributes also to the evolution of traditional concepts and to the development of legal theory.

Last but not least, we should not underestimate the political dimension of evaluation. It strengthens the legislators' responsibility for the result of their decisions and thus improves the democratic functioning of the political institutions. It also creates the foundations for a critical-not only technocraticapproach to legislation. As a matter of fact, elucidating the gap between legislative intentions and the results achieved may be an impetus to the adaptation of legal norms. It may also enhance critical examination of the political institutions. It would be wrong, therefore, to consider evaluation just as a tool of social engineering. Its critical function is as important as its technocratic function. 